Portland State University

PDXScholar

Spring 2021

\title{
NHANES III Mortality Follow Up: Social Determinants Creating Disparity within the Health Outcomes of Persons with Diabetes
}

Claire B. Adams

Portland State University

Follow this and additional works at: https://pdxscholar.library.pdx.edu/honorstheses

Part of the Clinical Epidemiology Commons, Community Health and Preventive Medicine Commons, and the Endocrinology, Diabetes, and Metabolism Commons Let us know how access to this document benefits you.

\section{Recommended Citation}

Adams, Claire B., "NHANES III Mortality Follow Up: Social Determinants Creating Disparity within the Health Outcomes of Persons with Diabetes" (2021). University Honors Theses. Paper 1131.

https://doi.org/10.15760/honors.1162

This Thesis is brought to you for free and open access. It has been accepted for inclusion in University Honors Theses by an authorized administrator of PDXScholar. Please contact us if we can make this document more accessible: pdxscholar@pdx.edu. 
NHANES III Mortality Follow Up: Social Determinants Creating Disparity within the Health Outcomes of Persons with Diabetes

Claire B. Adams ${ }^{1}$ and Carlos J. Crespo, DrPH ${ }^{2}$

${ }^{1}$ Portland State University Honors College, ${ }^{2}$ OHSU-PSU School of Public Health 


\begin{abstract}
Given the recent research into the social determinants affecting health outcomes, the goal of this thesis is to examine whether a non-urban setting, among other social determinants of health, increases the risk of mortality among the United States diabetic population. We examined the relationship of urban and non-urban diabetes rates among those aged 40-74 years using a national sample of diabetic and nondiabetic Americans. The data was pulled from the Third National Health and Nutrition Examination Survey (NHANES III) which was conducted from 1988 to 1994. After excluding pregnant women, those who did not complete a fasting AM glucose, and those with missing information on variables for our analysis, a total of 3,219 American subjects (1,635 women and 1,584 men) were studied. Our results show no significant association between urban living and dying with diabetes. However, we found a significant interaction between urban living and insurance status in predicting diabetes mortality among persons with diabetes. Further research should investigate the influence of having health insurance in urban and rural settings. Therefore, expanding research on the social determinants of health currently impacting diabetes mortality rates has the potential to influence the work being done by healthcare professionals to address access within rural communities. Keywords: National Health and Nutrition Examination Survey (NHANES), NHANES III, social determinants of health, health disparities, Centers for Disease Control and Prevention (CDC)
\end{abstract}




\section{Introduction}

Effective management and care of persons with diabetes in America has become an increasing challenge within the Public Health community over the past several decades ${ }^{1}$. As one of the most rapidly growing chronic diseases, diabetes has placed a growing economic burden on the United States healthcare system and the American taxpayers, with an approximately $26 \%$ rise in diabetic healthcare costs from $2015-2017^{2}$. In 2019 , a study found the mean annual direct cost per person was between $\$ 220$ and $\$ 7,600$, with medications and hospitalizations contributing to the majority of the costs ${ }^{3}$. Given the high cost incurred by those with diabetes, access to consistent health insurance coverage, whether private or public, is associated with improved diabetes care management and health outcomes ${ }^{4}$. Diabetes is associated with a multitude of risk factors, therefore proper access to care is pivotal in preventing negative health outcomes and higher rates of mortality.

The common risk factors for diabetes studied and discussed by the majority of those in the discourse community revolve around the individuals smoking status, obesity, and physical inactivity, amongst others. However, what if those are just the foundation for a larger issue at hand? One must look at the social determinants of this disease. In reality, the social determinants of health are just as likely, if not more, to have an impact on the risks and health outcomes of those with diabetes ${ }^{5}$. This goes beyond the associated comorbidities of the disease instead focusing on the conditions in which people were born in, raised, and currently live. Although all the social determinants of health play essential roles in health effects, "geography and health are intrinsically linked. Where we are born, live, study and work directly influences our health experiences: the air we breathe, the food we eat, the viruses we are exposed to and the health 
services we can access" ${ }^{6}$. Traditional clinical interventions for health continue to create gaps of care and access for those whose social determinants place them at a disadvantage to others. Clinical outcomes for persons with diabetes continue to be highly influenced by social determinants of health, many of which still lack proper research and policy-based solutions ${ }^{5}$. As the number of persons living with diabetes continues to increase, providing proper care necessary to reduce associated health outcomes and mortality becomes an increasingly important issue for the Public Health community to tackle. Based on the most recent estimates by the Center for Disease Control (CDC), there are an estimated 34.2 million Americans, or 10.5\% of the population, living with diabetes ${ }^{2}$. The CDC also estimates that approximately 88 million people adults have prediabetes ${ }^{2}$. With proper preventative medicine and constant healthcare access, the progression to type 2 diabetes mellitus for these 88 million people is preventable. Diabetes is associated by many long-term comorbidities which currently lead to more adult cases of blindness, renal failure, and amputations than any other disease in America ${ }^{7}$. Prevention of this disease is necessary to keep healthcare costs down, as well as communities in good health. Yet, for rural people, these geographic barriers to healthcare access continue to exacerbate the prevention of proper management of the disease ${ }^{5}$. These barriers are not limited to zip code alone but encompass other obstacles in health such as proximity to public parks, safe places to walk or exercise, food security, and a primary care physician or a needed specialist nearby.

\section{Methods}

The NHANES III study is a nationwide probability sample of 39,695 people aged 2 months and older which was conducted from 1988 to 1994 in two phases ${ }^{8}$. This Diabetic Mortality follow-up study was performed through linking the death certificate data available in the National Death Index (NDI) to the NHANES III data. To perform our analysis, we excluded 
women who were pregnant at the time of the study, those who did not complete a morning fasting glucose blood test, those outside of the 40-74 year age range, and those with missing variables necessary for our analysis. Our analytic sample includes the remaining 3,219 persons with complete data on diabetes status.

All analysis was conducted using the statistical software SAS 9.4 program. We used Cox Proportional Hazards Models to investigate the association between the mortality of persons with diabetes while controlling for exposures in insurance status and geographic areas. We used the geographic areas urban and non-urban as defined and published by NHANES III study. The age range of 40-74 was selected given a relative stability with education and income levels within this age group and that this age group completed an Oral Glucose Tolerance Test.

\section{Results}

After analysis using SAS 9.4, we were left with the subjects shown in Table 1, which were then further evaluated by exposure to urban and non-urban residence, as seen in Table 2.

\begin{tabular}{lcc} 
Table 1. Description of Subjects & \multicolumn{1}{c}{ Men $(95 \% \mathrm{CI})$} & \\
\hline & $53.96(53.19-54.72)$ & $54.57(53.68-55.46)$ \\
Age, years & & $51.00(49.00-53.00)$ \\
Race & & $56.53(53.83-59.22)$ \\
Non-Hispanic Whites, \% & $49.00(47.00-51.00)$ & $50.50(46.95-54.04)$ \\
Non-Hispanic Blacks, \% & $43.47(40.78-46.17)$ & $51.00(44.53-57.46)$ \\
Mexican Americans, \% & $49.50(45.96-53.05)$ & \\
Other race/ethnicity, \% & $49.01(42.54-55.47)$ & $25.00(22.17-27.83)$ \\
& & $37.60(34.70-40.48)$ \\
Education Level & & $37.24(33.29-41.18)$ \\
Less than High School, \% & $27.56(23.55-31-56)$ & \\
High School, \% & $25.49(21.62-29.35)$ & \\
More than High School, \% & $46.75(42.73-50.76)$ & $90.63(88.16-93.09)$ \\
Insurance status & & \\
Yes, \% & & \\
Urban Residence & $92.56(89.42-95.66)$ & \\
Yes, \% & & \\
\hline
\end{tabular}


Table 2. Demographic Distribution According to Exposure Variable (Urban vs. Non-Urban)

\begin{tabular}{llc}
\hline & \multicolumn{1}{c}{ Urban Residence } & Non-Urban Residence \\
\cline { 2 - 3 } Sex & $\%(95 \% \mathrm{CI})$ & $\%(95 \% \mathrm{CI})$ \\
Men, \% & $50.12(47.01-53.24)$ & $47.16(45.06-49.25)$ \\
Women, \% & $49.88(46.76-52.99)$ & $52.84(50.75-54.94)$ \\
& & \\
Age, years & $54.18(52.13-55.24)$ & $54.35(53.34-55.36)$ \\
& & \\
Race & & $87.19(83.73-90.65)$ \\
Non-Hispanic Whites, \% & $70.41(63.70-77.11)$ & $6.82(4.83-8.80)$ \\
Non-Hispanic Blacks, \% & $11.25(8.72-13.78)$ & $2.91(2.02-3.80)$ \\
Mexican Americans, \% & $4.50(3.04-5.95)$ & $3.08(1.13-5.04)$ \\
Other race/ethnicity, \% & $13.85(7.83-19.88)$ & \\
& & \\
Education Level & & $29.87(24.60-35.13)$ \\
Less than High School, \% & $22.03(17.83-26.22)$ & $34.58(31.43-37.74)$ \\
High School, \% & $28.38(24.67-32.10)$ & $35.49(30.22-40.76)$ \\
More than High School, \% & $49.24(43.90-54.59)$ & \\
Insurance status & & \\
Yes, \% & $90.13(86.17-94.09)$ & \\
\hline
\end{tabular}

Then based on the demographic distribution, the subjects where categorized based on the exposure to the outcome variables (diabetes mellitus status or non-diabetes status) which appears in Table 3. 


\begin{tabular}{|c|c|c|}
\hline & Diabetes Mellitus $(95 \% \mathrm{CI})$ & No Diabetes $(95 \% \mathrm{CI})$ \\
\hline \multicolumn{3}{|l|}{ Sex } \\
\hline Men, \% & $57.70(50.49-64.90)$ & $39.57-36.21-42.93$ \\
\hline Women, \% & $42.30(35.10-49.51)$ & $60.43(57.07-63.79)$ \\
\hline Age, years & $59.03(57.17-60.90)$ & $51.58(50.82-52.33)$ \\
\hline \multicolumn{3}{|l|}{ Race } \\
\hline Non-Hispanic Whites, \% & $12.52(10.64-14.41)$ & $44.92(41.13-48.71)$ \\
\hline Non-Hispanic Blacks, \% & $17.26(14.28-20.25)$ & $31.35(27.51-35.20)$ \\
\hline Mexican Americans, \% & $22.57(19.37-25.77)$ & $28.33(24.81-31.82)$ \\
\hline Other race/ethnicity, $\%$ & $10.35(5.51-15.20)$ & $33.01(23.35-42.66)$ \\
\hline \multicolumn{3}{|l|}{ Education Level } \\
\hline Less than High School, \% & $35.36(26.77-43.95)$ & $17.02(14.23-19.81)$ \\
\hline High School, \% & $37.86(28.49-47.23)$ & $30.25(26.60-33.90)$ \\
\hline More than High School, \% & $26.78(17.09-36.48)$ & $52.63(48.37-56.88)$ \\
\hline \multicolumn{3}{|l|}{ Insurance status } \\
\hline Yes, \% & $90.24(84.39-96.08)$ & $92.61(90.09-95.13)$ \\
\hline \multicolumn{3}{|l|}{ Urban Residence } \\
\hline Yes, \% & $41.80(30.71-52.89)$ & $46.80(36.53-57.07)$ \\
\hline
\end{tabular}

Lastly to examine the role of insurance coverage among those in urban and non-urban residence, Table 4 shows the prevalence of diabetes according to these variables. As seen here, when exposed to non-urban residence and lack of health insurance coverage, there is a 17.51 prevalence of diabetes compared to the appropriate exposures (8.61 prevalence).

\begin{tabular}{ll}
$\begin{array}{l}\text { Table 4. Prevalence of Diabetes According to Health Insurance Status } \\
\text { in Urban and Non-Urban Areas }\end{array}$ \\
\hline
\end{tabular}


Given the exposures, to examine the Hazard Risk for diabetes mortality and the interaction with urban and non-urban residence, as well age and insurance coverage status the Cox Proportional Hazard Model was applied to the data (Table 5).

Table 5. Cox Proportional Hazard Models

\begin{tabular}{lll}
\hline & \multicolumn{1}{c}{ Living in Non-Urban Area } \\
\cline { 2 - 3 } Model 1. Diabetes mortality & \multicolumn{1}{c}{ HR $(95 \% \mathrm{CI})$} & $\mathrm{N}$ \\
\cline { 2 - 3 } $\begin{array}{l}\text { Model 2. Diabetes mortality } \\
\text { adjusted for age }\end{array}$ & $1.117(0.85-1.55)$ & 57 \\
$\begin{array}{l}\text { Model 3. Diabetes mortality } \\
\text { adjusted for age and health } \\
\text { insurance status }\end{array}$ & $1.079(0.804-1.449)$ & 55 \\
\hline
\end{tabular}

\section{Discussion}

The most meaningful findings from this mortality study concerns the mortality of those with diabetes who live in a non-urban setting without health insurance coverage. Living in an urban setting was not a predictor for dying with diabetes. However, there was a predictive significance with a $\mathrm{P}=0.0006(H R=2.191$ (1.43-3.356) $)$ between people without health insurance and non-urban counties for a model ran with the Cox Proportional Hazard. But due to the minute sample size in the model, we were unable to further stratify the study population. Among the small sample size being a limitation to our study, there were many people with missing variables that were unable to be included, missing variables with the specific category of insurance coverage, and no differentiation between type 1 and type 2 diabetes mellitus. These limitations, along with a lack of health insurance and non-urban residency, exhibit the need for future research within the Public Health and endocrinology community. A longitudinal study which 
focuses on people with diabetes in rural and urban communities and their access to consistent healthcare is needed.

In highlighting the role of insurance coverage combined with geographic location it exposes the potential barriers present to access proper healthcare for those with diabetes.

Figure 1. Free Clinic Locations by State, as of May 2015

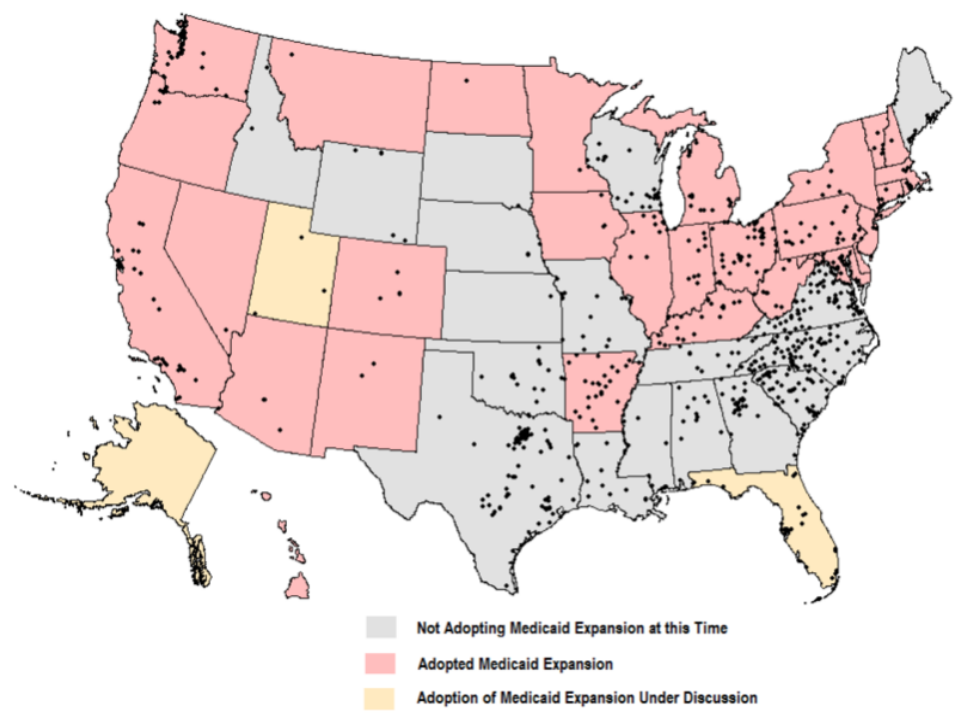

Source: The Henry J. Kaiser Family Foundation ${ }^{10}$

According to a recent study, adequate access to primary care is associated with potential healthcare savings related to preventable hospitalizations for those living in rural areas that are uninsured $^{9}$. This calls for further attention to the association present with geographic areas and health insurance coverage. However, insurance coverage only explains a portion of this issue. Access to healthcare for those in rural areas may be just as, if not more, important. Does having health insurance provide immediate access to a healthcare provider or is this access only determined by one's geographic location? 
Given that only $22 \%$ of free clinics within the United States are located in rural areas compared to $78 \%$ in urban areas, those without health insurance in rural areas are left at a notable disadvantage ${ }^{10}$. Not only are many rural counties at a disadvantage, but there are also seventeen states without a single free clinic within a rural area ${ }^{10}$. As shown in Figure 1, those uninsured who do not live in or near rural communities are unable to access medical care within a reasonable distance. It can be assumed improved diabetes control could easily be attained through better access to healthcare ${ }^{11,12}$.

The social determinant of geographic location and environment plays an essential role in health outcomes impacting the social services provided which allow greater access to certain groups. Future research within this could provide insight into optimal future locations for free medical clinics and educational outreach programs for diabetes, as well as increase overall access to healthcare for disease prevention and management. This would allow for greater access to those who may be several hundred miles from their nearest specialist. Adequate access to consistency in healthcare could be the key to lowering negative health outcomes, mortality rates, and providing economic savings for those living with diabetes ${ }^{13}$. 


\section{References}

1. Centers for Disease Control and Prevention. National Diabetes Statistics Report, 2020. Atlanta, GA: Centers for Disease Control and Prevention, U.S. Dept of Health and Human Services; 2020.

2. American Diabetes Association. Economic costs of diabetes in the U.S. in 2017. Diabetes Care. 2018;41(5):917-928. doi:10.2337/dci18-0007

3. Ramzan S, Timmins P, Hasan SS, Babar Z-U-D. Cost analysis of type 2 diabetes mellitus treatment in economically developed countries. Expert Review of Pharmacoeconomics \& Outcomes Research. 2018;19(1):5-14. doi:10.1080/14737167.2018.1513790

4. Doucette ED, Salas J, Scherrer JF. Insurance coverage and diabetes quality indicators among patients in NHANES. Am J Manag Care. 2016;22(7):484-490.

5. Walker RJ, Strom Williams J, Egede LE. Influence of Race, Ethnicity and Social Determinants of Health on Diabetes Outcomes. Am J Med Sci. 2016;351(4):366-373. doi:10.1016/j.amjms.2016.01.008

6. Dummer TJB. Health geography: Supporting public health policy and planning. Canadian Medical Association Journal. 2008;178(9):1177. doi:10.1503/cmaj.071783

7. Crandall JP, Knowler WC, Kahn SE, et al. The prevention of type 2 diabetes. Nat Clin Pract Endocrinol Metab. 2008;4(7):382-393. doi:10.1038/ncpendmet0843

8. NHANES III (1988-1994). Centers for Disease Control and Prevention. https://wwwn.cdc.gov/nchs/nhanes/nhanes3/default.aspx

9. Zhang W, Mueller KJ, Chen LW. Uninsured hospitalizations: rural and urban differences. J Rural Health. 2008;24(2):194-202. doi:10.1111/j.1748-0361.2008.00158.x 
10. Martin A, Bhavsar G, Workman L, Probst JC. Free Clinics in the Rural Safety Net, 2014. South Carolina Rural Health Research Center. September 2015:1-11

11. Gertz AM, Frank S, Blixen CE. A survey of patients and providers at free clinics across the United States. Journal of Community Health. 2010;36(1):83-93. doi:10.1007/s10900-010-9286-x

12. McLendon SF, Wood FG, Stanley N. Enhancing diabetes care through care coordination, telemedicine, and education: Evaluation of a rural pilot program. Public Health Nurs. 2019;36(3):310-320. doi:10.1111/phn.12601

13. Mallow JA, Theeke LA, Whetsel T, Barnes ER. Diabetes group medical visits and outcomes of care in low-income, rural, uninsured persons. Open J Nurs. 2013;3(3):314-322. doi:10.4236/ojn.2013.33043 